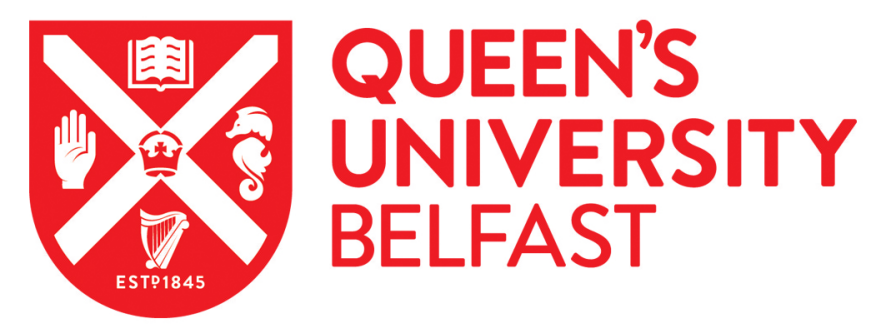

\title{
Experiences of offenders with traumatic brain injury
}

Linden, M. A., O'Rourke, C., Monaghan, C., \& Rainey, D. (2021). Experiences of offenders with traumatic brain injury. Brain Impairment, 22(1), 108 - 123. https://doi.org/10.1017/Brlmp.2020.23

\author{
Published in: \\ Brain Impairment
}

\section{Document Version:}

Peer reviewed version

Queen's University Belfast - Research Portal:

Link to publication record in Queen's University Belfast Research Portal

\section{Publisher rights}

Copyright 2020 the authors.

This is an open access article published under a Creative Commons Attribution-NonCommercial-NoDerivs License

(https://creativecommons.org/licenses/by-nc-nd/4.0/), which permits distribution and reproduction for non-commercial purposes, provided the author and source are cited.

\section{General rights}

Copyright for the publications made accessible via the Queen's University Belfast Research Portal is retained by the author(s) and / or other copyright owners and it is a condition of accessing these publications that users recognise and abide by the legal requirements associated with these rights.

Take down policy

The Research Portal is Queen's institutional repository that provides access to Queen's research output. Every effort has been made to ensure that content in the Research Portal does not infringe any person's rights, or applicable UK laws. If you discover content in the Research Portal that you believe breaches copyright or violates any law, please contact openaccess@qub.ac.uk. 


\title{
Experiences of offenders with traumatic brain injury.
}

Authors: Mark A. Linden, Conall O’Rourke, Catherine Monaghan, \& Deborah Rainey

\begin{abstract}
Purpose: Traumatic brain injury is recognised as a significant and pervasive health issue among offender populations. Despite this, no qualitative research exists exploring the experiences and perceptions of offenders with TBI in prison.
\end{abstract}

Methods: Qualitative interviews were conducted with male and female offenders housed in a UK prison. Interviews examined what participants felt led them to offend, experiences of incarceration, and post-release plans. Presence of TBI was assessed via the Brain Injury Screening Index. Data were analysed by means of inductive content analysis.

Findings: Both male and female prisoners primarily attributed their incarceration to drugs and alcohol use, with males also referencing more issues with aggression, while mental illness and past abuse were more commonly mentioned among females. A lack of recognition for the possible role of TBI was noted, with several males describing themselves as "stupid" or prone to making "poor lifestyle choices”. Both groups indicated a desire to return to education or work post-release,

Conclusions: Despite significant rates of injury, there is a clear lack of understanding and consideration of the role of TBI in the behaviour and presentation of offenders. There is need for improved identification and education around TBI early in the criminal justice process.

Keywords: traumatic brain injury, offender, prisoner, qualitative, perceptions 


\section{Introduction}

Traumatic brain injury (TBI) is increasingly recognised as a significant health concern among offender populations, with meta-analyses estimating prevalence of TBI in the overall offender population to be $60.25 \%$ (Shiroma et al., 2010). Two systematic reviews by O’Rourke, Linden, Lohan, and Bates-Gaston (2016) and Hughes, Williams, and Chitsabesan (2015) also highlighted rates as high as 71\% among young offenders and $88 \%$ among adult offenders. The exact nature of the relationship between TBI and offending remains unclear, though recent studies have sought to draw causal links between TBI and subsequent crime (Williams et al., 2018).

Equally important to consider are the challenges offenders with TBI may experience in the criminal justice system (CJS). Offenders with TBI have been reported as committing a greater number of behavioural infractions while in prison, relative to offenders without injury (Merbitz et al., 1995; Shiroma et al., 2010).. The strict and inflexible environment of prison may place particular strain on offenders with TBI, impacting on both their adaption to prison life and their subsequent readiness for release. Behavioural problems associated with TBI, such as impulsiveness, in-attention, or a lack of emotional awareness, may cause offenders to act inappropriately in stressful or confrontational situations (Diamond et al., 2007; Schofield et al., 2006; Shiroma et al., 2010). For prison officers, such behaviours may be interpreted as simply bad behaviour rather than the result of self-regulation and aggression difficulties. Repeated reprimand of offenders with TBI may be counter-intuitive to reducing such aggression, particularly if offenders are unable to control their behaviours. Given that TBI is a disability in which outward signs of injury are not always apparent, offenders with TBI risk having their disability overlooked and being deemed more culpable for their impairments than individuals with more visible injuries. Such misattributions have been suggested to result in carers explaining aggressive behaviours as being the result of the individual's 
personality or moral weakness rather than an understandable consequence of the TBI (Giles et al., 2013).

This misattribution and stigmatisation of behaviour may also be an issue among offenders themselves. A lack of understanding around the possible presence and symptoms of TBI may deter offenders from seeking medical help (O’Rourke et al., 2018). TBI outcomes in this group can be particularly negative, with offenders with TBI being twice as likely to develop psychiatric disorders (Ray et al., 2014) and present with greater drug use (Walker et al., 2011), relative to offenders without injury. It is important to consider not only whether a relationship exists between TBI and subsequent risky or illegal behaviours, but whether offenders recognise this link and understand the possible role TBI may play in their behaviour. Previous work by O’Rourke and colleagues (2017) highlighted that probation services may rely on offenders themselves to communicate their TBIs during pre-sentencing interviews. Offenders who are unaware or do not understand their injuries may therefore fail to have their needs identified within the CJS.

The current study sought to explore the beliefs and perceptions held by offenders with TBI regarding their incarceration. While a number of studies now exist examining TBI among this population, to the author's knowledge, only one other study has employed qualitative methods with this group. Recent work by Lansdell and colleagues (2018) examined the experiences of people with Acquired Brain Injury (ABI) in the justice system in Victoria, Australia. Though this work focused on stakeholder groups such as judges, lawyers, and service providers, a small number $(n=22)$ of ex-prisoners were recruited. Evident from the results was the belief that the current systemic responses to TBI do little to prevent offending and, in some cases, may actively create pathways to offending. Furthermore, the cognitive, emotional, and behavioural issues associated with TBI were perceived as significant disadvantages during interactions with the justice system. It should be noted that 
participants were aware of their injuries, and the authors acknowledged that stakeholders often took part because of their relevant expertise and knowledge on the topic. Data published from our participants (offenders within prison) in a previous paper showed that they differed significantly from those of Lansdell et al. (2018) as they were unaware that they had a TBI (Linden et al., 2020). Only three participants out of 54 reported being told that they had received an injury (Linden et al., 2020). Furthermore, the current study differs in focus, examining offender's beliefs around their cause of incarceration and post-release plans. The aim of the current study was therefore to explore the beliefs and perceptions of offenders with TBI about their cause of incarceration, experiences of prison, and post-release plans.

\section{Methods}

\section{Design}

A cross-sectional structured interview design was employed to gather demographic and TBI data, while three open-ended qualitative questions were used to explore the beliefs and experiences of young male and adult female offenders currently housed at a secure prison in Northern Ireland. The appropriate ethical approvals were gained prior to data collection (ref: 15/NI/0011). Quantitative data has been presented elsewhere (Linden et al., 2020; O’Rourke et al., 2018). The current paper describes our qualitative findings.

\section{Participants and setting}

The study was conducted in a young offender centre and adjoining women's prison in Northern Ireland between October 2015 and July 2016. The prison housed young male offenders between the ages of 18 and 21 years in addition to adult female offenders aged above 18 years. At the time of data collection, the prison held a population of 134 young male offenders and 59 female offenders, though actual prisoner numbers varied over time. 
Logistical difficulties, including staff shortages, unexpected schedule changes, and limited access hours, restricted the total accessible population. A total of 37 young male offenders and 17 female offenders provided qualitative responses to the questions posed. No set inclusion criteria were used, though participants were required to understand and speak English.

\section{Materials}

A questionnaire was administered through structured interview to all participants which collected data on participant characteristics, offence history, and history of TBI. Participant characteristics included; gender, age, number of criminal convictions, age at first offence, past medical and mental health diagnoses, medication, education, and maternal education (as a proxy of socioeconomic status).

TBI Screening: The Brain Injury Screening Index (BISI) is a 7-item tool, validated for the identification of TBI in offender populations (Pitman et al., 2014). Questions relate to number of injuries to the head, loss of consciousness and post-injury care. A TBI-index score is produced by multiplying the lengths of consciousness, in minutes, by the number of injuries.

Qualitative questions: Participants were asked three open-ended questions, which sought to gain insight into their past, present and future experiences;

1. What do you feel led you to offend?

2. What has been your experience of incarceration?

Prompt 1 . What has been your experience of the other young men/women? Prompt 2. What has been your experience with staff?

3. Have you thought about your plans for after release? 
Due to security concerns, audio recording of participant responses was not permitted. Prison security measures excluded the transport of all outside electronic equipment onto secure premises. As such, handwritten notes were taken during each response and verbally relayed back to individuals as a check on accuracy.

\section{Procedure}

The purpose of the research was advertised throughout the male and female wings of the prison by means of a poster. Potential participants were offered to the opportunity to meet with a member of the research team to learn more about the project, read an information sheet and ask any questions they had about the work. Those who expressed an interest in taking part provided their name and prison identification number which were given to the prison booking department to arrange a suitable interview time. Interviews took places in a quiet room were participants were asked to read and sign the consent form. Participants were then asked the three open ended questions described above.

\section{Data Analysis}

Qualitative data were examined using NVivo 12 (NVivo Ltd 2015). Due to the reliance on handwritten notes, the data was deemed unsuitable for in-depth thematic analysis. Inductive content analysis was therefore employed as a method of categorising responses into single concepts. This method is recommended for conducting exploratory work and allows for simple reporting of common issues identified in the data (Green 2004). Data taken from the notes were transcribed, organised by question and gender, and read through for familiarisation. Key words were then identified through word frequency searches and organised into primary themes. Word clouds were also created in NVivo from these frequency searches to display the most common responses to questions 1 and 3 . Responses to each question were subsequently re-organised into each dominant theme based upon the use 
of key words or synonyms. Transcripts were then searched through for supporting quotes and explanatory responses around each identified theme.

A number of steps were employed to ensure rigour. Whilst it was not possible to audio record interviews, the researcher made comprehensive, verbatim notes which fully captured interviewees accounts. Member checking was undertaken following completion of each interview to ensure the handwritten notes were an accurate reflection of participants’ experiences. Meetings between team members were held to discuss and agree upon the generated codes. Two team members led on this with a third available to arbitrate any disagreements. Lastly, an audit trail was retained to ensure an accurate account of the data collection process, analysis and interpretation would be available for scrutiny.

\section{Findings}

\section{Participant demographics}

Demographic and clinical information for the male $(n=37)$ and female $(n=17)$ offenders is shown in Table 1. As this was a prison for adult female and young male offenders these groups varied greatly in terms of average age (Females $=32.53$ years, Males $=19.57$ years). The highest level of education for the majority of participants was primary school $($ Females $=44.4 \%$, Males $=56.8 \%)$. Maternal education was employed as a proxy measure for socioeconomic status (SES) and showed that both males and females came from low SES backgrounds. Mothers of female offenders were educated to primary school level (22.2\%), whilst mothers of male offenders were educated to secondary school level (21.6\%). Rates of mental illness were higher amongst female offenders (83.3\%) than males (62.5\%), however, there was little difference shown between groups on alcohol abuse (Females = $61.1 \%$, Males $=59.5 \%)$.

\section{Insert table 1 about here}




\section{Perceived causes of incarceration}

Male responses were categorised into five themes. The three primary themes were “Substance Abuse”, “Anger/Aggression”, and "Perceptions of Consequence” characterised by an inability to perceive the consequences of their behaviours. Male offenders also referenced a combination of "peer influence” and "negative familial environments" as precursors and influencers of their subsequent criminal behaviour. Figure 1 displays the most frequently mentioned words.

\section{Insert figure 1 about here}

A significant proportion of males blamed either drug addiction or alcohol abuse for their incarceration. Alcohol use was often reported as a precursor to violent behaviour, with one male noting “... Turns me into a nasty fella. If I never drank, I would've never met the police” (Male, 6 injuries), and another commenting “It was a drunken mistake. Two fellas jumped me and I hit one with a bottle” (Male, 3 injuries). Among those who reported drug use/addiction as the precursor to offending, both actions to fund drug habits, and decisions made while under the influence of drugs were salient, "I had to pay off drug deals every week... I got some money from mum... I got away with a few things so I kept going” (Male, 3 injuries), “Drugs were my big downfall. If I wasn't off my head I wouldn't have done those things... wouldn't have hit him” (Male, 5 injuries). Such notable overlap between substance use and aggressive or violent behaviours reflects the prevalence of “Anger/Aggression” as a theme among respondents.

Though aggression was sometimes the result of alcohol or drug abuse, it was also characterised as a personality trait “...I made poor lifestyle choices... I was always fighting” (Male, 6 injuries) “Stupidity, bad decisions, and acting out of anger” (Male, 6 injuries). Some of this aggression appeared to be the product of environmental or socialisation factors " $\mathrm{I} g$ ot 
threw out of five homes for fighting... people my age liked to push you” (Male, 3 injuries), such that aggressive masculinity was a means of surviving or asserting strength. However, a number of offenders indicated that they struggled to control or monitor their anger. One individual remarked that it was his "Stupidity” and “... bad decisions” that resulted in him “[acting] out of anger" (Male, 6 injuries). Another noted that if he had of been able to "[talk] to people [I] wouldn't have ended up in this situation... wouldn't have resorted to violence" (Male, 2 injuries). Male offenders appeared to often be blinded by their anger, reacting before considering the consequences of their actions. One male described how a "Mate was slobbering [talking aggressively] and telling me he was going to do this and do that. I just cracked [hit] him".

Male offenders often referenced their inability to perceive the consequences of their criminal behaviours. Statements such as “I don’t think before doing things” (Male, 3 injuries) "I was stubborn and impulsive. I made bad decisions" (Male, 1 injury), and "Stupidity... already been down this road, but did it again” (Male, 4 injuries) repeatedly placed the blame on offenders themselves. One individual summarised this as “I don't think things through even though I know the consequences” (Male, 6 injuries), suggesting that even though these males understood that what they were doing was wrong, they struggled to perceive the immediate consequences of their actions, inhibit their negative behaviours, and identify the appropriate actions to take in particular situations.

There was notable overlap between drug use and negative peer influence, with several males indicating that friends had introduced them to drugs or were involved in pushing them into crime. There was a clear recognition of the negative influences of anti-social peers, though males often blamed themselves for being “talked into it” (Male, 2 injuries) or for not recognising “False friends” (Male, 2 injuries). Vulnerability to peer influence has been previously recognised as a risk factor for offending (Andrews \& Bonta 2010) and appears to 
play a key role in both drug and alcohol use. Individuals with TBI may be particularly vulnerable to such influence, failing to recognise when they are being taken advantage of or when the acts they are being "talked into" are of particular risk.

Family difficulties were also reported, where issues from abusive parenting, to challenging experiences in the care system were noted. One individual indicated that other members of his family were offenders "All my biological family is in jail... I have no role models" (Male, 3 injuries), and that his brother was also resident in the prison. Five other males made reference to issues in the home, ranging from criminal activity to being made homeless at an early age. For these males, offending appeared to be a consequence of the failings of others to support them whilst growing up. Drug use again featured heavily in these accounts, though this may have been more of a coping mechanism for the stress and trauma of such experiences. The impact of such negative early environments on TBI should also be considered, with individuals from difficult family backgrounds experiencing more severe and lasting consequences of TBI.

Among female offenders, "Substance Abuse" was also the dominant theme, followed by “Mental Illness”, “Relationship/Partner problems”, “Abuse” and “Peer Influence”. The most frequently mentioned words are presented in Figure 2.

\section{Insert figure 2 about here}

Substance abuse was also the dominant theme among female offenders, who noted that either heavy drinking, or drug usage, had led them to offend. While drug use appeared more as a lifestyle choice among males, females were clear in communicating drugs as an addiction which controlled many aspects of their lives. There was clear overlap between theft and addiction, with one female noting "I had a drug habit. I was a heroin addict with 80 charges for shoplifting” (Female, 6 injuries), and another stating “Gambling addiction... it led me to steal and that's why I'm here" (Female, 1 injury). While substance abuse was 
viewed as the main cause of subsequent offending, several females felt that other factors were to blame for this addiction.

The theme of "Relationship/Partner problems" was common alongside substance abuse with comments such as “Alcohol and men, it doesn't agree with me” (Female, 6 injuries). Women often described their experiences more in terms of their vulnerability than their criminal intent and were more likely than men to describe themselves as victims of abusive or coercive partners. As stated by one female "My husband was selling counterfeit goods and I got pulled into it” (Female, 1 injury). Difficult relationships appeared to pose particular stress and rarely occurred as isolated factors. As one woman described " $I$ was in a bad place... struggling with things... with relationships and money... things just got out of hand" (Female, 2 injuries).

In more extreme cases, women spoke of abusive partners and the struggles they faced in dealing with the results of abuse. One participant stated "I was sexually and physically abused, and I do drugs to block it” (Female, 1 injury) while another described the “Combination [of] abuse and my children were removed from me” (Female, 6 injuries). Despite a high rate of reported past abuse, only four women indicated a belief that this had contributed to their offending. Surprisingly, TBIs resultant of such abuse were not mentioned, with females placing greater emphasis on the emotional trauma experienced over the physical trauma. This may represent a failure to acknowledge the impact of such repeat injuries, with females more likely to attribute subsequent mental health problems to emotional trauma rather than a TBI.

Victimisation often ran alongside themes of mental illness, where instead of an abusive or coercive partner, females described themselves as victims of a care system which failed to address their needs. One participant described this experience as "I didn't have the 
resources and help out there... I begged for mental health and alcohol services" (Female, 3 injuries), while another blamed "Neglect from institutions, and my mental illness as well" (Female, 1 injury). One female described how she "had a breakdown - I have mental health issues and my son was sexually abused. No help was there for me, it pushed me over the edge." Women were more vocal regarding the contributory impact that mental illness had on incarceration than men.

Only two participants mentioned possible brain injury as a contributing factor to their behaviour "I'd like to get my brain properly checked. I definitely feel different since [my injury]” (Female, 3 injuries), "[I was] assaulted in the head in primary school... everything went downhill after that” (Male, 2 injuries). The lack of a strong narrative linking brain injury to offending among this population supports earlier findings by this group (O’Rourke et al., 2018) that awareness of the consequences of brain injury, and the possible impact on behaviour, is not understood by offenders.

\section{Experiences of incarceration}

Overall, experiences of incarceration for both men and women were mixed, though many considered that the current prison setting was "alright”. Several respondents noted that it offered them space to develop as a person and provided opportunities to learn new things through the available education programmes "teachers do as much for you as possible" (Male, 6 injuries), “you get the attention you need to grow up and learn” (Male, 6 injuries). Notable differences between male and female responses included the tendency for males to describe their experience as "easy", comparing the facility to a holiday camp or youth club. Comparisons such as these may have been intended to exhibit the "manliness" of participants, suggesting that they did not perceive their time in prison as punishment "It was a gift. It's a holiday camp in here. I'm used to it from coming in and out... you get used to it" (Male, 3 injuries). However, as noted by another male "[It is] Difficult. If they [other 
offenders] tell you it's easy they are lying” (Male, 6 injuries). Females were much more critical however, believing the healthcare and mental health facilities to be significantly lacking. Respondents noted "there is no support for addicts” (Female, 6 injuries), “... there is not enough counselling” (Female, 3 injuries), and “there's only one [staff member] I can speak to. He talks me down when I'm self-harming” (Female, 3 injuries). While one male reported "I was waiting two weeks when I came in to be seen. I was on heroin and they wouldn't detox me” (Male, 3 injuries), no male respondents commented on the mental health facilities. This again may reflect a need to appear tough and hide any signs of vulnerability, despite demographics characteristics (see table 1) indicating that mental illness was a significant issue among this group. Another potential reason for participants describing the prison environment as "easy" could relate to its highly structured nature which inadvertently supports impairments in executive functioning (Linden et al., 2020). For some, the prison environment, with its rules and checks, may prove easier than their 'outside' lives which are often chaotic and disruptive (Elbogen et al., 2015).

As with overall impressions of prison, comments about fellow prisoners were mixed for both males and females. Males within the prison are divided based upon reward status, with the best behaved or "enhanced" offenders residing in one building (block) and those with poorer behaviour, or who routinely failed drug tests residing in a separate "basic" status block. This divide was clearly noted among offenders, with individuals on "enhanced” status described as "calm and wanted to get the time done" (Male, 3 injuries) while individuals on “basic” status were described as having a tendency to “...fuck about” (Male, 2 injuries). While such a divide is intended to act as a motivation for the improvement of behaviour, it may in fact serve to re-enforce the "offender” identity of individuals with TBI resulting in further behavioural infractions. One resident on "basic" status described others on his landing as "Childish... taking drugs and failing tests” (Male, 4 injuries) while another summarised 
this group as “one week out, three months in [prison]” (Male, 3 injuries). Individuals from this block were often looked down upon as untrustworthy individuals to be avoided, while those in the “enhanced” block were “100\%” (Male, 1 injury) and “dead on” (Male, 6 injuries). Expressions of aggression among males took a more physical form than among females, often due to "people trying to be dominant" (Male, 6 injuries). One male described how "a guy slapped me but you couldn't hit him back because you are waiting on bail” (Male, 4 injuries), while another described how he "had to break one of their noses" (Male, 6 injuries) because they disrespected him. Responding to disagreements with violence appeared the norm, with one participant apprehensively describing how he had not "come to blows with anyone yet” (Male, 2 injuries).

All females were housed in a single building, which resulted in a complex mix of individuals on each floor. As such, women were more selective about who they associated with, one woman noted "most of them are off their faces [high on drugs]. A few of them are grand [Good] though” (Female, 1 injury). The dynamic of relationships was also notably different among females relative to males, with less violent or aggressive conflicts noted. Instead, it was noted that women "have their own cliques" (Female, 3 injuries) which would intimidate or bully others, “...you have to fight your corner. They would try to set you up...vindictive... they reported I had drugs in my cell." "If someone's getting bullied you can't help her or everyone turns on you... If told to, others will avoid that person” (Female, 2 injuries). While outward aggression was mentioned less frequently, hostility appeared to manifest through “bitchy [behaviour] particularly for new people coming in” (Female, 2 injuries).

Impressions of staff were also mixed for both genders, with some reporting positive interactions “[staff are]... really brilliant, very helpful” (Female, 6 injuries), "they have to be firm, but they do have a good side” (Female, 1 injury), "[staff are] lovely, you get respect 
when you give respect" (Male, 4 injuries), "they do their best, you have to empathise with what they put up with" (Male, 1 injury) and others reporting negative impressions "some are wankers" (Male, 3 injuries), "slimy, tell you one thing and then something else happens" (Male, 2 injuries), "Some go out of their way to annoy you” (Male, 2 injuries), “[they are] Two faced... think they're better than everyone else” (Female, 6 injuries), “Awful, I was assaulted by two staff... they threw me to the ground. I'm very wary of the staff, I don't interact [with them]" (Female, 2 injuries). There was a clear sense from offenders that several of the staff disliked their work and so would employ authoritarian approaches when dealing with individuals. This was often perceived by offenders as an abuse of power, with one female describing how officers would "make life miserable" (Female, 6 injuries). Such abuses of power led to distrust and resentment alongside a feeling of stigmatisation "[some officers] ...look at you like scum” (Male, 3 injuries). Particularly worrying was the perception that certain officers would provoke offenders they knew struggled with aggression in order to "get hit so they can get six months [off with] full pay" (Male, 4 injuries). The position of power held by prison officers was well understood by offenders, and how an officer was perceived as using (or abusing) that power had significant implications for their relationships with offenders.

\section{Expectations of life following release}

Among the post-release goals of male offenders, the dominant theme reported was "Employment”. Males also placed significant emphasis on "Family" "Education” and "Accommodation" though a number also reported that they had not or did not want to think about post-release. As displayed in Figure 3, while employment was the key goal, male offenders placed significant importance on starting families and raising their children.

\section{Insert figure 3 about here}


The majority of male offenders prioritised a return to work post-release. It was felt that returning to their old job or securing new employment was the first step in re-integrating into society and many had indicated forward planning on how to achieve this "Get a job in catering, I have a level two course education but want to work to level three" (Male, 6 injuries), "My brother owns a company. I worked for him before and the job is waiting" (Male, 4 injuries), “[I am] meant to be back to Harland and Wolff [manufacturing company based in Belfast]. If not then I will get work through a mate in a hotel or go back to the shop with dad" (Male, 4 injuries). The level of planning and thought put in to employment goals varied between individuals, "I'm going to be a rapper, like Eminem. [There is] a lot of overlap in how we both grew up” (Male, 2 injuries), “[I want to] set up a business selling personalised $t$-shirts, mugs, and calendars and get it funded by the national lottery" (Male, 2 injuries). The challenge many offenders face when attempting to follow through on their plans was noted by one offender "guys go out with the impression they can do this and that and end up turning back to drugs" (Male, 4 injuries).

Tied closely to employment was the desire to provide for their family or to build a life with their partners and children. Seven males indicated already having children, though for others this was described as “what everyone wants, kids, a girlfriend, a job” (Male, 1 injury). Starting a family was also considered a turning point or sign of adulthood, that males had matured beyond their past crimes, “Now I have kids, I want to be a better person” (Male, 6 injuries), “[I want to] Get my family back together... I proposed a few weeks before coming in, she's sorting it. We're planning it for two years... She's been there for me all the way through, I want to treat her to a nice wedding” (Male, 3 injuries). This may also have been considered a way of shifting from being identified as an "offender”, to developing the identity of a father and provider. 
Among many of those who wished to return to work, returning to education or upskilling was also a key goal. Statements such as “I'm working in a catering course... I'm on a level 2 [qualification] and building to a level 3... If I get this, there'll be a big improvement” (Male, 3 injuries), “I want to be a personal trainer... I'm getting my level 2 in Maths and English” (Male, 1 injury), "[I want to] Go to tech [technical college] to do engineering... I'll do the basics here to go back to school”' (Male, 6 injuries) indicated a drive to improve upon participants' levels of low educational attainment. As with employment, it was unclear whether offenders had considered the possible barriers to education they may face.

While the majority of male offenders had put some thought into their plans post release, a small number reported either having not thought about this, or not wanting to think about it. For some, this appeared to be the result of fear, trying to protect themselves from disappointment and pain “I don’t know. No point in making plans... if you have no plans, no expectations, you never get hurt” (Male, 2 injuries). For others, it seemed difficult to focus on anything other than their current incarceration “Can't think about it until 12 months before I get out” (Male, 3 injuries), "I'm never coming back. I'll decide when I'm out. I don't know” (Male, 3 injuries). The stress and difficulties of coping with incarceration may leave offenders unable to think about the future, particularly for those on long custodial sentences.

Among half of female offenders, "Employment” also represented the primary goal following release. Themes of "Returning to family" and "Education" were also evident, with only two respondents indicating they did not know or had not thought about their plans postrelease. Figure 4 displays the words most frequently identified from transcripts.

\section{Insert figure 4 about here}


Many of the same goals were expressed by females as males. Again, offenders recognised employment and education as representing key steps in their re-integration into society. Several women planned to return to their pre-incarceration occupations, noting they wanted to “... go back to my sales job” (Female, 6 injuries), “get my business [personal trainer] back" (Female, 2 injuries), "I need to get back to work, I was self-employed as a cleaner" (Female, 5 injuries). For others, prison had provided them with the training to seek out further education "[I plan to] go to tech [technical college]. Study catering or something" (Female, 6 injuries). Another noted they were "taking a coaching course" within the prison gym, and saw themselves "training and working in the gym” following release (Female, 6 injuries). There was clear acknowledgement of the benefits to education and training, with many viewing the programmes offered as a stepping stone to bettering themselves upon release.

Possible barriers to such re-integration were not mentioned however, despite a significant number acknowledging the impact of their drug abuse and mental illness on offending. There appeared to be a general lack of awareness of potential pitfalls and barriers individuals with co-occurring TBI, drug abuse and mental illness may face. While the controlled environment of prison may have aided in female offenders' access to education, many females were of the belief that they could simply "Get back on track” (Female, 6 injuries) or pick-up where they left off. Only two females indicated a lack of planning for the future, with one stating they had “Nothing planned, I don't know. I want a better life than the last few years, I'm never coming back” (Female, 1 injury) and another describing release as being “Back to square one. Until something else happens - I will be back in here again no doubt about that” (Female, 4 injuries). Both responses indicated markedly different beliefs regarding post-release. The latter response suggested a strong offender identity, such that she was powerless to change her situation. This response, though extreme, did indicate a certain 
degree of recognition regarding the challenges she would face upon release. Nonetheless, it also suggested a sense of hopelessness or having given in to her circumstances which may also indicate that she felt the factors which contribute to her offending had not been addressed within prison.

\section{Discussion}

The aim of the current study was to examine the perceptions held by offenders with TBI regarding their incarceration. Evident from the findings was a distinct lack of awareness, understanding, and consideration of the potential presence and role of TBI in this population. Despite significantly high reported rates of injury (87\% among males, $72 \%$ among females), less than a third of individuals reporting passed head injuries believed themselves to have a TBI. This lack of consideration was further exemplified in the lack of individuals reporting TBI or past head injuries as possible contributors to their offending behaviour. Researchers have noted how a lack of insight following TBI can result in a failure to understand how impairments affect daily functioning, which can lead to unrealistic expectations concerning future aspirations (Fleminger et al., 2003). Lack of insight is also related to behavioural problems (Spikman et al., 2013) which may provide part of the picture in explaining how offenders become involved with criminal justice. Repeated reference to substance abuse, aggression, and mental illness among participants in the current study suggests that the potential role of TBI in offending is not recognised among prisoners.

\section{Perceived causes of incarceration}

Findings provided further insight into the perspectives of offenders regarding their incarceration. Individuals were clear in acknowledging the central role played by drug and alcohol abuse, as well as the impact of mental health and traumatic events on offending. 
While many accepted personal blame for their offences, such as those attempting to fund drug habits, for some, blame was related to institutional failings and support networks. Research by Bernasco and colleagues (2013) on adolescent offenders supports this, noting that the effects of both alcohol and drug use can induce and facilitate offending. Felson and colleagues (2012) found that both psychosis and major depression had strong impacts on aggression-based infractions within prison. Work by Brennan and colleagues (2012) examining pathways to serious and habitual crime in women reported similar gender differences to the present findings. They emphasised the role of abuse and trauma, mental illness, and parental/relationship dysfunction in female pathways to crime, that is not seen to the same degree in males. Despite the majority of both male and female offenders reporting past TBIs, only two participants indicated that they believed a TBI had contributed to their behaviour. This was particularly surprising among males, with a number of respondents describing how uncontrolled acts of aggression or violence led to their incarceration. Blame for such outbursts was largely internalised, with some male offenders referencing themselves as "stupid” or “impulsive”. Such traits may simply reflect the behavioural regulation and inhibition problems seen following TBI, with individuals misattributing their cause. Similarly, while females often characterised themselves as being "in a bad place” or "pushed over the edge”, they failed to connect such traits with possible underlying emotional dysregulation and poor adjustment strategies. Such a lack of insight into the potential role of TBI in offending behaviour may also contribute to the development of an "offender" identity, whereby individuals perceive themselves, or their uncontrollable attributes, as being criminal. Believing yourself to be a criminal without consideration of why you behave or think in a certain way may impact an offender's propensity to seek out appropriate help or support. It has been noted that individual's with TBI can possess an intellectual awareness of their behaviour but can fail to apply this to real world settings (Crosson et al., 1989). The 
understanding that they have acted aggressively, or how drugs and alcohol have led to their offending in the past, can have little influence on how they behave on release from prison. This goes part way to explain the high rates of repeat offenders with TBI we see in our prisons. In order to identify individuals who possess this disparity between what is said and what is done it is necessary to perform multiple assessments, by trained case workers, whilst also drawing information from the individual and third party sources (Holloway \& Fyson, 2016).

\section{Experiences of imprisonment}

While both groups acknowledged a lack of services within prison, females were more likely to mention their continued struggles with mental illness and the lack of counselling and support services offered. Both the presence of drugs and lack of available services were raised as concerns in recent prison inspection reports (Brennan et al., 2012; Felson et al., 2012). Specifically, the mental health team was described as ill-equipped to meet the needs of women with learning disabilities, autism spectrum disorders, post-traumatic stress disorder or personality disorders. This was coupled with what inspectors deemed as inadequate mental health screening upon first arrival at the prison. Women with emotional or mental health

problems (55\%, 15/27) described not being supported by anyone in the prison, with only $27 \%$ of respondents reporting the quality of healthcare available as good or very good (Crimial Justice Inspection NI 2016). This lack of support is particularly worrying in the context of TBI. Given that only three male offenders and four female offenders reported ever being told they had a TBI, many prison health professionals may not consider or even realise the possible presence and impact of past injuries on their service users.

\section{Post-incarceration goals}

Failure to recognise and address TBI resultant deficits may have significant consequences for post-release goals. While the majority of both male and female offenders 
indicated that employment was their primary goal upon leaving prison, few commented on the potential challenges they may face in securing and maintaining employment. While the stigma associated with prison is likely to negatively impact attempts to gain employment or access education, the significant health issues identified within this sample must also be recognised. High rates of drug abuse and mental illness coupled with significant gaps in healthcare may hamper an individual's opportunities for rehabilitation and thus leave them ill prepared for release. Though several offenders indicated a wish to go back to education or start a business, without recognition of their possible TBI and an understanding of how this may impact upon their attentional, emotional, and behavioural abilities, many offenders may struggle to achieve these goals. Maintaining focus, planning ahead and managing responsibility, and dealing with stressful or confrontational situations in an appropriate way are all key skills required for education and employment. Offenders who have not been provided with adaptation and compensation techniques for TBI resultant deficits will likely struggle to come to terms with their shortcomings. A lack of insight into the presence of their injuries may also increase the risk of self-blame and a subsequent "return to old ways" following such failure. While it was positive to see such a large proportion of the sample planning and considering their options post-release, focus should be placed on ensuring such goals are realistic. In working with offenders with TBI, criminal justice services should focus on ways to accommodate and support TBI resultant deficits, whilst ensuring that offenders fully understand the implications of their injuries.

\section{Strengths and Limitations}

This study is the first to the authors' knowledge to employ qualitative methods in examining TBI among young male and female offenders in prison. However, several limitations should be noted. The study relied on self-report of injuries from individuals who may have experienced past TBIs. While previous work has suggested that offenders are 
reliable respondents (Schofield et al., 2011) it is possible that injuries were forgotten or misremembered. Security restrictions meant that audio recording of offender interviews was not permitted, and data collection was limited to handwritten notes. Although responses were verbally relayed back to offenders to check accuracy, balancing the recording of responses with ensuring a natural flow of discussion was challenging. The limited interview time further hampered efforts to extract qualitative responses, with offenders often keen to return to their scheduled activities or classes. This posed further issues to the collection of trustworthy data and reflects one of the logistical challenges of conducting research within prison environments. Nonetheless, responses collected on the perceived reasons for incarceration provided valuable insights into the pre-incarceration environment of offenders. It further highlighted offender perceptions of the centrality of drug and alcohol use, mental illness, and abuse, alongside the absence of recognition for TBI in the factors that contribute to offending behaviour.

\section{Conclusions}

Greater acknowledgement of the vulnerability of female offenders is needed. With a predominant focus upon male offenders in the literature, further research is needed to examine the causes, co-occurrences, and outcomes for female offenders with TBI. This finding also re-affirms that TBI screening should be made available for all offenders upon entry into the CJS.

There is a need to recognise that despite differences in presentation, TBI has a significant impact upon an offender's ability to regulate their thoughts and actions. Such vulnerability may manifest in rule breaking behaviour, susceptibility to negative peer influence, and acting without consideration of consequence. Without recognition of the underlying cause of their behaviours, offenders risk misinterpreting such difficulties as their own failing or "stupidity". It is important to note the duty of care owed to offenders by the 
CJS. Offenders have a right to be informed that they have a TBI and should have the possible consequences of injuries explained to them. While those working with offender groups should be better trained in identifying and responding to such deficits, offenders themselves require a greater understanding of the impact of past injuries, and the available strategies to compensate for such impairments.

At a more basic level, increasing recognition and understanding around TBI and its resultant deficits among offenders represents a key starting point for addressing these problems. A one size fits all approach may not be appropriate given the differing needs and outcomes expressed by males and females. While both groups indicated drug and alcohol abuse as the primary cause of offending, males spoke more of issues with aggression, while females indicated greater feelings of victimisation. Interventions targeted at these groups should account for these differences and consider the differing challenges these issues may pose in achieving post-release goals.

\section{FINANCIAL SUPPORT}

This research received no specific grant from any funding agency, commercial or not-forprofit sectors.

\section{CONFLICT OF INTEREST}

No conflicts of interest have been declared by the authors

\section{ETHICAL STANDARDS}


The authors assert that all procedures contributing to this work comply with the ethical standards of the relevant national and institutional committees on human experimentation and with the Helsinki Declaration of 1975, as revised in 2008.

\section{References:}

Andrews, D. A., \& Bonta, J. (2010). The psychology of criminal conduct. Routledge.

Bernasco, W., Ruiter, S., Bruinsma, G. J., Pauwels, L. J., \& Weerman, F. M. (2013).

Situational Causes of Offending: A fixed-effects analysis of space-time budget data. Criminology, 51(4), 895-926.

Bradley, R., Sapp, D., \& Kincaid, A. (2014). Traumatic brain injury among Indiana state prisoners. Journal of Forensic Sciences, 59(5), 1248-53.

Brennan, T., Breitenbach, M., Dieterich, W., Salisbury, E. J., \& Van Voorhis, P. (2012).

Women's pathways to serious and habitual crime: A person-centered analysis incorporating gender responsive factors. Criminal Justice and Behavior, 39(11), 14811508.

Criminal Justice Inspection Northern Ireland. (2016). Report on an unannounced inspection of Ash House Women’s Prison Hydebank Wood 9-19 May 2016.

Crosson, B., Barco, P. P., Velozo, C. A., Bolesta, M. M., Cooper, P. V., Werts, D., \& Brobeck, T. C. (1989). Awareness and compensation in postacute head injury rehabilitation. Journal of Head Trauma Rehabilitation, 4(3), 46-54.

Diamond, P., Harzke, A., Magaletta, P., Cummins, G., \& Frankowski, R. (2007). Screening for traumatic brain injury in an offender sample: A first look at the reliability and validity of the traumatic brain injury questionnaire. The Journal of head trauma rehabilitation, 22(6), 330-38. 
Elbogen, E. B., Wolfe, J. R., Cueva, M., Sullivan, C., \& Johnson, J. (2015). Longitudinal predictors of criminal arrest after traumatic brain injury: Results from the traumatic brain injury model system national database. Journal of Head Trauma Rehabilitation, 30(5), E3-E13.

Felson, R. B., Silver, E., \& Remster, B. (2012). Mental disorder and offending in prison. Criminal Justice and Behavior, 39(2), 125-143.

Fleminger, S., Oliver, D. L., Williams, W. H., \& Evans, J. (2003). The neuropsychiatry of depression after brain injury. Neuropsychological Rehabilitation, 13(1-2), 65-87.

Giles, G. M., Scott, K., \& Manchester, D. (2013). Staff-reported antecedents to aggression in a post-acute brain injury treatment programme: What are they and what implications do they have for treatment. Neuropsychological Rehabilitation, 23(5), 732-754.

Green, J., \& Thorogood, N.. (2004). Analysing Qualitative Data. Silverman D(ed.). Qualitative Methods for Health Research (1st edn). London:Sage Publications.

Holloway, M., \& Fyson, R. (2016). Acquired brain injury, social work and the challenges of personalisation. British Journal of Social Work, 46(5), 1301-1317.

Lansdell G, Saunders B, Eriksson A, Bunn R, \& Baidawi S. (2018). 'I am not drunk,I have an ABI’: Findings from a qualitative study into systematic challenges in responding to people with acquired brain injuries in the justice system. Psychiatry, Psychology and Law, 25(5), 737-758.

Linden, M., O’Rourke, C., \& Lohan, M. (2020). Traumatic brain injury and social competence among young male offenders. Disability \& Rehabilitation, 42(17), 24222429.

Merbitz, C, S Jain, GL Good, \& A Jain. 1995. Reported head injury and disciplinary rule infractions in prison. Journal of Offender Rehabilitation, 22(3-4), 11-19.

NVivo qualitative data analysis software; QSR International Pty Ltd. Version 12, 2018. 
O’Rourke, C, Linden, M., \& Lohan, M. (2017). Misconceptions about traumatic brain injury among probation services. Disability and Rehabilitation, 40(10), 1119-1126.

O’Rourke, C., Linden, M., \& Lohan, M. (2018). Traumatic brain injury and abuse among female offenders compared to non-incarcerated controls non-incarcerated controls. Brain Injury, 32(13-14), 1787-94.

Pitman, I., Haddlesey, C., Ramos, S., Oddy, M., \& Fortescue, D. (2014). The association between neuropsychological performance and self-reported traumatic brain injury in a sample of adult male prisoners in the UK. Neuropsychological Rehabilitation, 25(5), 763-79.

Schofield, P., Butler, T., Hollis, S., \& D’Este, C. (2011). Are prisoners reliable survey respondents? a validation of self-reported traumatic brain injury (TBI) against hospital medical records. Brain injury, 25(1), 74-82.

Schofield, P., Butler, T., Hollis, S., Smith, N., Lee, S. \& Kelso, W. (2006). Traumatic brain injury among australian prisoners: rates, recurrence and sequelae. Brain injury, 20, 499-506.

Shiroma, E., Pickelsimer, E., Ferguson, P., Gebregziabher, M., Lattimore, P., Nicholas, J., Dukes, T., \& Hunt, K. (2010). Association of medically attended traumatic brain injury and in-prison behavioral infractions: A statewide longitudinal study. Journal of Correctional Health Care, 16(4), 273-86.

Shiroma, E., Ferguson, P., \& Pickelsimer, E. (2010). Prevalence of traumatic brain injury in an offender population: A meta-analysis. Journal of Correctional Health Care, 16(2), $147-59$.

Spikman, J. M., Milders, M. V., Visser-Keizer, A. C., Westerhof-Evers, H. J., HerbenDekker, M., \& van der Naalt, J. (2013). Deficits in facial emotion recognition indicate 
behavioral changes and impaired self-awareness after moderate to severe traumatic brain injury. PLoS ONE, 8(6), e65581.

Walker, R., Hiller, M., Staton, M., \& Leukefeld, C. (2011). Head injury among drug abusers: An indicator of co-occurring problems. Journal of psychoactive drugs, 35, 343-53.

Williams WH, Chitsabesan P, Fazel S, McMillan T, Hughes N, Parsonage M. \& Tonks J. (2018). Traumatic brain injury: A potential cause of violent crime? The Lancet Psychiatry, 5(10), 836-844. 
Table 1. Characteristics of offenders by gender

\begin{tabular}{|c|c|c|}
\hline & Females $(\mathrm{N}=17)$ & Males $(\mathrm{N}=37)$ \\
\hline Age (years), mean (SD) & $32.53(8.87)$ & $19.57(1.07)$ \\
\hline Number of convictions, mean (SD) & $15.50(26.79)$ & $30.13(30.66)$ \\
\hline Age at first conviction, mean (SD) & $21.78(12.01)$ & $14.65(2.60)$ \\
\hline \multicolumn{3}{|l|}{ Education N (\%) } \\
\hline Primary school & $8(44.40)$ & $21(56.8)$ \\
\hline GCSE/equivalent & $3(16.7)$ & $8(21.6)$ \\
\hline Apprenticeship & 0 & $3(8.1)$ \\
\hline Certificate/Diploma & $5(27.8)$ & $4(10.8)$ \\
\hline A-Level/equivalent & $1(5.6)$ & $1(2.7)$ \\
\hline \multicolumn{3}{|l|}{ Maternal Education N (\%) } \\
\hline Primary school & $4(22.2)$ & $4(10.8)$ \\
\hline GCSE/equivalent & $3(16.7)$ & $8(21.6)$ \\
\hline Apprenticeship & 0 & $3(8.1)$ \\
\hline Certificate/Diploma & $3(16.7)$ & $4(10.8)$ \\
\hline A-Level/equivalent & $1(5.6)$ & $1(2.7)$ \\
\hline University Degree & 0 & 0 \\
\hline Postgraduate Degree & $1(5.6)$ & 0 \\
\hline Unknown & $5(27.8)$ & 0 \\
\hline \multicolumn{3}{|l|}{ Number of TBI N (\%) } \\
\hline 1 & $3(16.7)$ & $2(5.4)$ \\
\hline 2 & $2(11.1)$ & $11(29.7)$ \\
\hline 3 & $3(16.7)$ & $6(16.2)$ \\
\hline 4 & $1(5.6)$ & $5(13.5)$ \\
\hline 5 & 0 & $3(8.1)$ \\
\hline 6 & $8(44.4)$ & $10(27.0)$ \\
\hline \multicolumn{3}{|l|}{ Most Severe Injury N (\%) } \\
\hline No LOC & $2(11.1)$ & $10(27.0)$ \\
\hline LOC $<10$ mins & 7 (38.9) & $12(32.4)$ \\
\hline LOC $<6$ hours & $6(33.3)$ & $12(32.4)$ \\
\hline LOC > 6hours & $2(11.1)$ & $3(8.1)$ \\
\hline
\end{tabular}




\begin{tabular}{|l|c|c|}
\hline Drug Abuse N (\%) & $12(66.7)$ & $31(83.8)$ \\
\hline Alcohol Abuse N (\%) & $11(61.1)$ & $22(59.5)$ \\
\hline Mental Illness N (\%) & $15(83.3)$ & $23(62.5)$ \\
\hline
\end{tabular}

*General Certificate in Secondary Education (GCSE) is a school qualification offered in the United Kingdom to students aged between $14-16$ years. ${ }^{* *}$ Advanced level (A-level) is a school qualification offered in the United Kingdom to students aged between $16-18$ years 




Figure 1. Most frequently reported responses to question one for males: What do you feel led you to offend? 


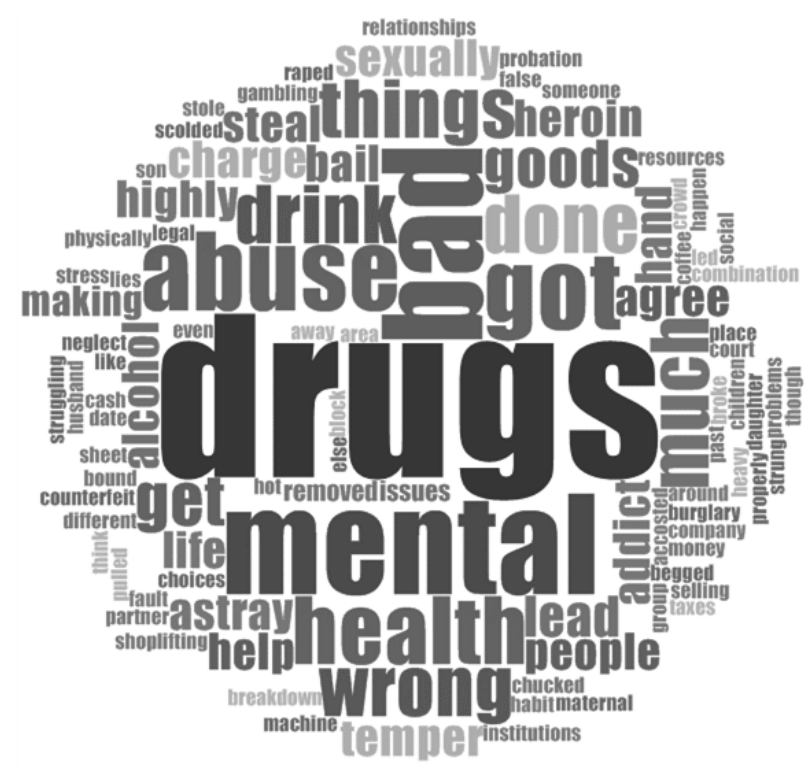

Figure 2. Most frequently reported responses to question one for females: What do you feel led you to offend? 


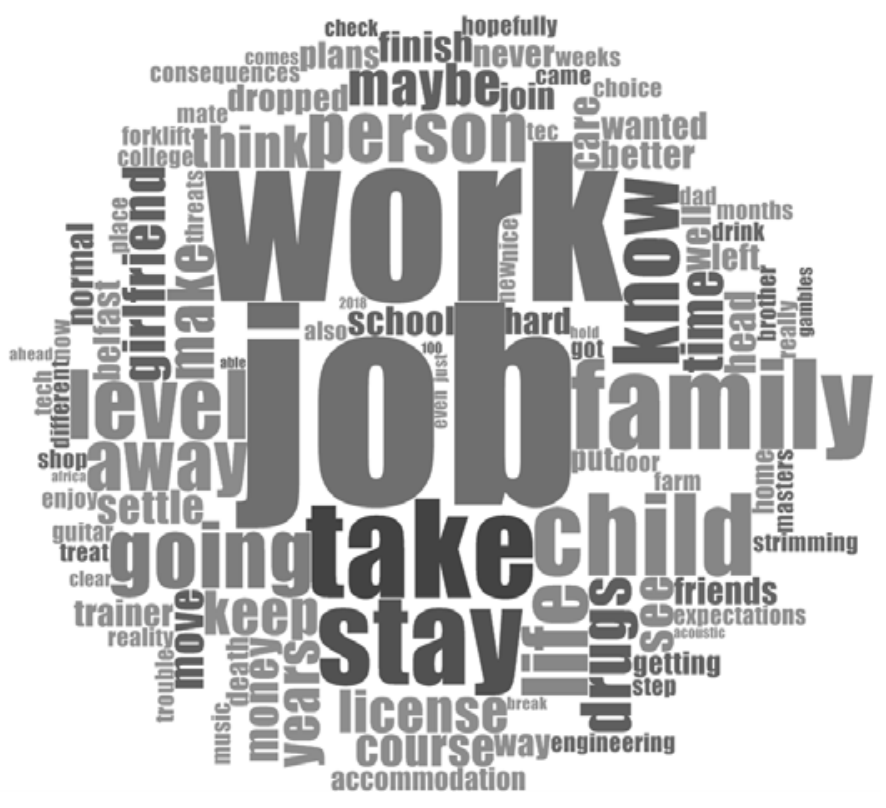

Figure 3. Most frequently reported responses to question three for males: Have you thought about your plans for after release? 


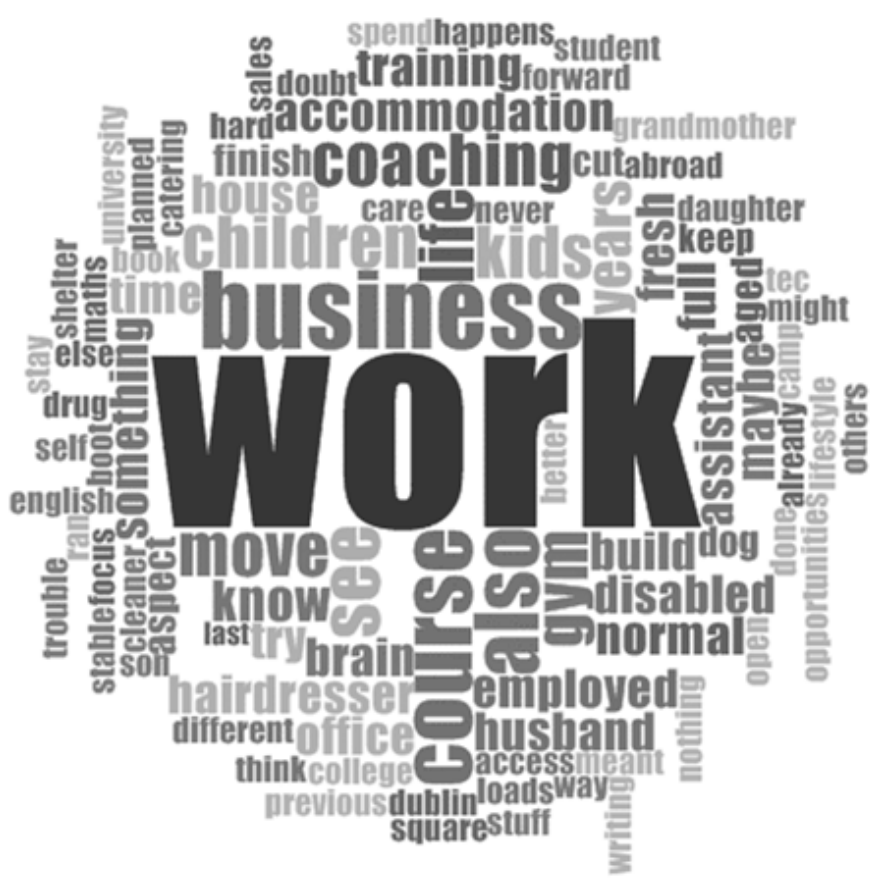

Figure 4. Most frequently reported responses to question three for females: Have you thought about your plans for after release? 